\title{
Morphologic variability of the mitral valve leaflets
}

\author{
Agata Krawczyk-Ożóg, MD, ${ }^{\mathrm{a}, \mathrm{b}}$ Mateusz K. Hołda, MD, PhD, ${ }^{\mathrm{a}, \mathrm{c}}$ Danuta Sorysz, MD, PhD, ${ }^{\mathrm{b}}$ \\ Mateusz Koziej, MD, ${ }^{\text {,cc }}$ Zbigniew Siudak, MD, PhD, ${ }^{\mathrm{b}}$ Dariusz Dudek, MD, PhD, ${ }^{\mathrm{b}}$ and \\ Wiesława Klimek-Piotrowska, MD, $\mathrm{PhD}^{\mathrm{a}, \mathrm{c}}$
}

\section{ABSTRACT}

Objectives: The rapid development of surgical and less-invasive percutaneous mitral valve repair procedures has increased interest in mitral valve anatomy. We characterize the morphologic variability of the mitral valve leaflets and provide the size of their particular parts.

Methods: We studied 200 autopsied human hearts from white individuals without any valvar diseases. We measured the intercommissural and aorto-mural diameters of the mitral annulus and identified the leaflets and their scallops. We also noted the base and the height of the inferoseptal commissure, superolateral commissure, anterior mitral leaflet, and posterior mitral leaflet with their scallops.

Results: Variations in posterior mitral leaflet were found in 55 specimens $(27.5 \%)$, and variations in anterior mitral leaflet were found in 5 hearts $(2.5 \%)$. The most common variations included valves with 1 accessory scallop between P3 and inferoseptal commissure (7\%), accessory scallop between P1 and superolateral commissure (4\%), connections of P2 and P3 scallops (4\%), connections of $\mathrm{P} 1$ and $\mathrm{P} 2$ scallops $(3 \%)$, and accessory scallop in anterior mitral leaflet $(2.5 \%)$.

Conclusions: In all cases, the mitral valve is built by 2 main leaflets with possible variants in scallops $(29.5 \%)$. The variations are largely associated with posterior mitral leaflet and are mostly related to the presence of accessory scallop. Anatomically, the anterior mitral leaflet is not divided into scallops, but could have an accessory scallop $(2.5 \%)$. Understanding the anatomy of the mitral valve leaflets helps with the planning and performing of mitral valve repair procedures. Variations in scallops may affect repair procedures, but unfortunately cannot be predicted by any of the annular sizes. (J Thorac Cardiovasc Surg 2017;154:1927-35)

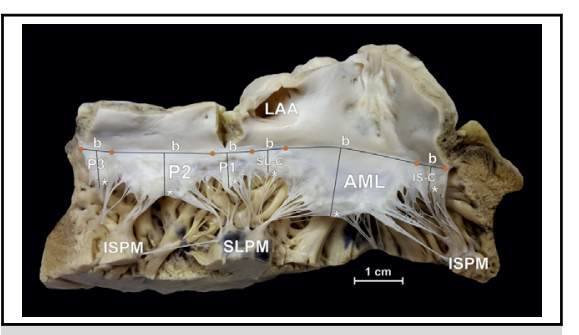

Cadaveric heart specimen showing classic mitral valve.

\section{Central Message}

Anatomic variants and morphometry of the mitral valve leaflets are shown, as well as the main distances between the mitral annulus and the adjacent structures in the 200 autopsied human hearts.

\section{Perspective}

The detailed knowledge about mitral valve anatomy is basic to the design and development of novel surgical and less-invasive strategies for mitral valve disease treatment. Precise understanding of the mitral valve complex could help in heart imaging, determining the planning, and performing procedures and thus avoid complications.

See Editorial Commentary page 1936.
Detailed knowledge of the mitral valve anatomy has been the interest of researchers since the early 20 th Century. ${ }^{1}$ The mitral valve complex consisted of the annulus, leaflets, commissures, tendinous cords, papillary muscles, and left atrial and ventricular walls, and is one of the most complicated mechanical arrangement in the human body. Failure

\footnotetext{
From ${ }^{\mathrm{a}}$ HEART - Heart Embryology and Anatomy Research Team, ${ }^{\mathrm{b}}$ 2nd Department of Cardiology and Cardiovascular Interventions, University Hospital, Institute of Cardiology, and ${ }^{\mathrm{c}}$ Department of Anatomy, Jagiellonian University Medical College, Krakow, Poland.

Received for publication April 19, 2017; revisions received June 26, 2017; accepted for publication July 13, 2017; available ahead of print Sept 8, 2017.

Address for reprints: Agata Krawczyk-Ożóg, MD, 2nd Department of Cardiology and

Cardiovascular Interventions, 17 Kopernika, Krakow 31-501, Poland (E-mail: krawczyk.ozog@gmail.com).

$0022-5223 / \$ 36.00$

Copyright $(2017$ by The American Association for Thoracic Surgery

http://dx.doi.org/10.1016/j.jtcvs.2017.07.067
}

of even 1 part of the complex may result in valvar dysfunction and significant harm to heart pump function. ${ }^{2}$

Mitral valve disease is one of the most prevalent valvar heart diseases. The rapid development of surgical and less-invasive percutaneous (MitraClip; Abbott, Abbott Park, Ill) mitral valve repair procedures has greatly increased the interest in mitral valve anatomy. ${ }^{3}$ The size of the leaflets and their scallops, the distance between the mitral annulus and adjacent heart structures, and other parameters of the mitral complex are important indicators

Scanning this QR code will take you to the article title page. 


\section{Abbreviations and Acronyms \\ AcS = accessory scallop \\ $\mathrm{AML}=$ anterior mitral leaflet \\ BMI = body mass index \\ $\mathrm{PML}=$ posterior mitral leaflet}

for selecting valve repair technique and approach. Also, imaging of the mitral valve during planning and performing invasive procedures, by echocardiography or computed tomography, requires excellent understanding of the normal mitral valve anatomy, as well as knowledge of its most common variants. ${ }^{4-7}$ This knowledge is basic to the design and development of novel strategies for mitral valve disease treatment. Thus, we aimed to characterize the morphologic variability of the mitral valve leaflets and determine the size of their particular parts.

\section{MATERIALS AND METHODS Study Population}

In this study, we included 200 autopsied human hearts from white individuals $(25 \%$ were female) with a mean age of $47.5 \pm 17.9$ years. The average body mass index (BMI) was $26.6 \pm 4.6 \mathrm{~kg} / \mathrm{m}^{2}$, and mean body surface area was $1.9 \pm 0.2 \mathrm{~m}^{2}$. Hearts were collected during routine forensic medical autopsies performed between July 2013 and June 2016. The causes of death were mainly suicide, murders, and traffic and home accidents. The exclusion criteria were severe anatomic defects, heart surgeries, evident severe macroscopic pathologies of the heart or vascular system found during autopsy (aneurysms, storage diseases), heart trauma, and macroscopic signs of cadaver decomposition. None of the 200 individuals had a history of any valvar disease or arrhythmia. This study was approved by the Bioethical Committee of Jagiellonian University.

\section{Dissection and Measurements}

The hearts were dissected together with the proximal portions of the great vessels and weighed before fixation. After dissection, all of the hearts were fixed by immersion in $10 \%$ paraformaldehyde solution for a maximum of 2 months until the time of measurement. ${ }^{8}$ The left atrium was opened in a routine way. We obtained linear measurements using $0.03-\mathrm{mm}$ precision electronic calipers (YT-7201; YATO, Wroclaw, Poland). To reduce potential bias, all measurements were made by 2 independent researchers. If the measurement differences between the researchers exceeded $10 \%$, both measurements were repeated. The mean of the 2 values was calculated and approximated to a tenth of a decimal place.

Before cutting the mitral annulus, the intercommissural and aorto-mural diameter of the mitral annulus were measured. The intercommissural diameter of the mitral annulus was measured as the longest medio-lateral distance along the line that connects both commissures (zone of apposition between the leaflets). The aorto-mural diameter was defined as a line perpendicular to the central part of the intercommissural diameter (Figure 1). Next, for better visualization, the mitral annulus was opened by an incision through the mitral isthmus line, which is defined as a line located between the left inferior pulmonary vein (or common left pulmonary vein) ostium and mitral valve annulus, and then the left ventricle wall was cut. ${ }^{9,10}$ The mitral annulus was defined as the D-shaped (saddle shaped) incomplete fibrous ring, marking by the hinge line of the valvar leaflets and commissures. ${ }^{2}$

Classic mitral valve type was defined as a valve with 2 main leaflets, a single anterior mitral leaflet (AML) and posterior mitral leaflet (PML)

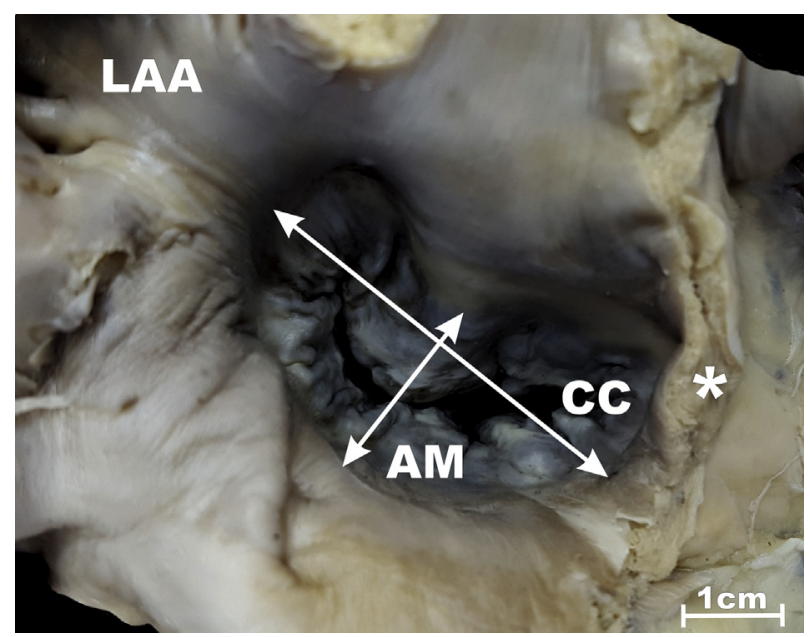

FIGURE 1. Cadaveric heart specimen. Left atrial view of the classic mitral valve with marked intercommisural and aorto-mural diameters. $L A A$, Left atrial appendage; $C C$, intercommisural; $A M$, aorto-mural. *Interatrial septum.

composed of 3 scallops-P1 (lateral), P2 (middle), and P3 (medial)both connected with commissures and without any abnormalities in the anatomic structure. Precise criteria were applied to identify the commissures, leaflets, and their associated scallops. First, we recognize the inferoseptal and superolateral commissures, mainly by its characteristic appearance and the presence of the commissural tendinous cord, which originate solely from the respective papillary muscle located beneath the commissure and runs as a single stem that branches radially resembling the ribs of a fan, and thus referred to as a "fan-shaped chordae." This allowed us to identify main leaflets and to distinguish the scallops within the leaflets. The characteristic patterns of tendinous cords attachments to the free edges of the valve leaflet and their further branching were the main criteria for scallop identification. In addition, indentations and thinning of the tissues were helpful to demarcate parts of the mitral valve. On the basis of the origin of the tendinous cords from the superolateral or inferoseptal papillary muscles, the P2 scallop of the PML was found. Then the P1 and $\mathrm{P} 3$, as well as accessory scallops (AcSs), if present, were named. Figure 2 shows the classic mitral valve with the discussed parts annotated.

All critical points of identified parts of the mitral valve were marked by pins. Measurements of the following dimensions were obtained in all leaflets, scallops, and commissures: the base (or circumferential length),

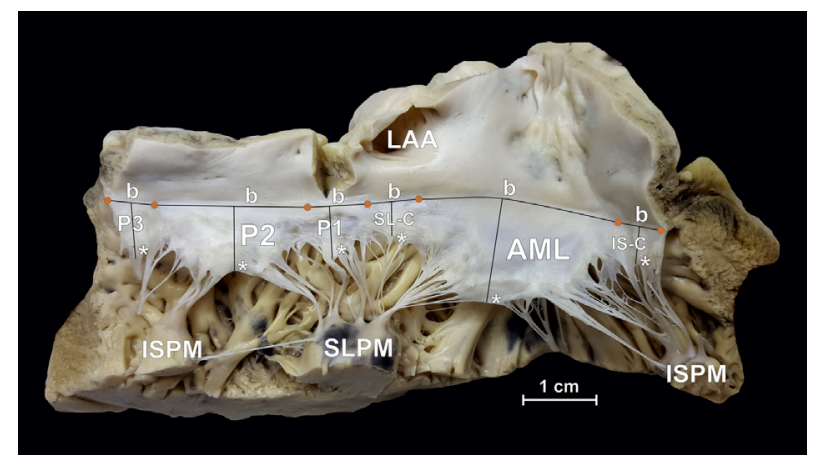

FIGURE 2. Cadaveric heart specimen. Classic mitral valve. Base $(b)$ and height (*) of the AML, PML scallops (P1, P2, and P3), and superolateral and inferoseptal commissures are marked. $L A A$, Left atrial appendage; $S L-C$, superolateral commissure; $A M L$, anterior mitral leaflet; $I S-C$, inferoseptal commissure; ISPM, inferoseptal papillary muscles; SLPM, superolateral papillary muscles. 
measured alongside the attachment line (hinge) to the mitral annulus, and the height, the maximum distance from the mitral annulus attachment point (hinge) to the free edge, measured in the central part of the base (Figure 2). The circumference of the mitral annulus (along the attachment line of the leaflets, from the atrial surface) was obtained. The mitral annulus area was calculated using the following bespoke formula, developed by our team:

$$
M A A=\frac{1}{4} \times \pi \times C C \times \frac{4}{3} A M-\frac{1}{6} A M \times \sqrt{b A M L^{2}-\left(\frac{1}{3} A M\right)^{2}}
$$

where MAA is the mitral annulus area, CC is the intercommissural diameter, $\mathrm{AM}$ is the aorto-mural diameter, and bAML is the base of the anterior leaflet. The approximate surface area (A) of the leaflets and scallops were calculated using the formula:

$$
A=\pi \times \frac{\text { base } \times \text { height }}{4}
$$

The distance from the mitral annulus to the left atrial appendage ostium was measured. The distances from the mitral valve annulus to the left circumflex coronary artery and the great cardiac vein were measured at the level of mitral isthmus. ${ }^{11}$ Afterward, the mitral annulus was dissected, and the common part of the mitral and aortic annulus (intertrigonal distance) was measured.

\section{Statistical Analysis}

The data are presented as mean values and the corresponding standard deviations or percentages, as well as median with interquartile range. The Shapiro-Wilk test was used to determine if the quantitative data were normally distributed. To verify homogeneity of variance, Levene's test was performed. We also used the Student $t$ tests and Mann-Whitney $U$ tests for statistical comparisons. We performed Kruskal-Wallis 1-way analysis of variance to determine significant differences in the investigated heart parameters. Correlation coefficients were calculated to measure the statistical dependence between the measured parameters. We performed statistical analyses with STATISTICAv12 (StatSoft Inc, Tulsa, Okla).

\section{RESULTS}

The mean intercommissural diameter was $28.0 \pm 4.8 \mathrm{~mm}$. The mean circumference of the mitral annulus was $89.9 \pm 12.6 \mathrm{~mm}$, and the mean mitral annulus area was $485.4 \pm 171.4 \mathrm{~mm}^{2}$. There were significant statistical differences in these parameters between sexes, with the lower values observed for women $(P<.001, P=.02$, and $P=.002$ for intercommissural diameter, circumference of the mitral annulus, and mitral annulus area, respectively). The mean size of the aorto-mural diameter was $19.7 \pm 4.8 \mathrm{~mm}$. The mean intercommissural/aorto-mural diameter ratio in the studied hearts was $1.49 \pm 0.38$. The mean heart weight was $436.3 \pm 98.2 \mathrm{~g}$ and was correlated with the intercommissural diameter $(r=0.28 ; P<.001)$, aorto-mural diameter $(r=0.20 ; P<.004)$, mitral annulus circumference $(r=0.39 ; P<.001)$, and mitral annulus area $(r=0.30 ; P<.001)$. Correlations were found between the donor's age and the aorto-mural diameter $(r=0.31$; $P<.001)$, the mitral annulus area $(r=0.22 ; P=.002)$, and between the donor's weight and the mitral annulus circumference $(r=0.25 ; P<.001)$.

In all hearts, we were able to detect 2 commissures: superolateral and inferoseptal commissure and 2 main leaflets: AML and PML. The mean ratio of the AML base to the PML base was $0.7 \pm 0.2$. The AML encompasses $34.5 \% \pm 4.8 \%$ of the mitral annulus circuit and the PML encompasses $50.7 \% \pm 5.1 \%$. The remaining parts are reserved for commissures.

Classic mitral valve was found in 141 specimens $(70.5 \%)$. Detailed results of the leaflet, commissure, and scallop measurements in the classic type mitral valves are presented in Table 1. The borders of the AML were distinctly visible and noncontroversial, whereas the PML morphology was more difficult to assess. The PML had a longer base than the AML (45.1 vs $30.8 \mathrm{~mm} ; P<.001$ ) but had lower height (12.9 vs $20.6 \mathrm{~mm} ; P<.001)$. The AML had a larger approximate surface area than the PML $\left(504.9 \pm 159.2 \mathrm{~mm}^{2}\right.$ and $419.3 \pm 123.3 \mathrm{~mm}^{2}$, respectively; $\left.P<.001\right)$. Both commissures had a similar size. The PML could be divided into 3 scallops (P1, P2, P3). The medial (P3) had the lowest height $(P<.05)$ and the middle had the highest height $(P<.001)$, among other PML scallops. The middle (P2) scallop had the longest base $(P<.001)$. There was no difference between $\mathrm{P} 1$ and $\mathrm{P} 3$ base length. The $\mathrm{P} 2$ scallop had the biggest surface area $\left(\mathrm{P} 1=110.1 \pm 49.8 \mathrm{~mm}^{2} ; \mathrm{P} 2=202.9 \pm 80.2 \mathrm{~mm}^{2}\right.$; $\left.\mathrm{P} 3=107.1 \pm 51.1 \mathrm{~mm}^{2} ; P<.001\right)$. The AML was not divided into scallops.

All of the identified anatomic variations in the mitral valve leaflets are listed in Table 2. There were no significant differences in mitral valve leaflet variations between the sexes. Table 3 presents results of the measurements of the most common anatomic variations in the mitral valve. Most variations were located in the PML $(27.5 \%$ of all hearts). Single AcS in the PML (Figure 3) is the most commonly encountered (14\%) and could be located in any of the PML section, but it is mainly located between P3 and inferoseptal commissure (7\%). Two AcS in the PML (5 scallops in the PML) were found in $2 \%$ of hearts (Figure $4, A$ ). The PMLs with AcS have a longer base than classic PMLs $(52.4 \pm 9.9 \mathrm{~mm}$ vs $45.1 \pm 8.2 \mathrm{~mm}$; $P<.001)$ and greater mitral annulus circumference $(96.2 \pm 15.0 \mathrm{~mm}$ vs $89.1 \pm 11.8 \mathrm{~mm} ; P=.004)$. However, there were no significant differences in PML height; base and height of AML, superolateral commissure, and posterior leaflet commissure; mitral annulus area; or intercommissural and aorto-mural diameters. The AcS in PML had a shorter base than scallops in classic PML $(P<.001)$ and lower height than $\mathrm{P} 2(P<.001)$, but were similar to the $\mathrm{P} 1$ and $\mathrm{P} 2$. Also, the AcS in the PML was significantly smaller $(P<.05)$ when compared with other PML scallops in the same valve. Between-group analysis showed differences in BMI $(P=.04)$ between groups with (1) classic mitral valve $\left(26.1 \pm 4.4 \mathrm{~kg} / \mathrm{m}^{2}\right)$ and $(2)$ hearts with an AcS in the posterior leaflet $\left(28.5 \pm 4.4 \mathrm{~kg} / \mathrm{m}^{2}\right)$; however, we found this clinically irrelevant.

Another type of observed anomalies in the PML was the connection of the scallops $(9 \%$ ) (Figure $4, B)$. There were 
TABLE 1. Results of obtained morphometric measurements of classic type of mitral valve $(\mathrm{N}=141)$

\begin{tabular}{|c|c|c|c|c|c|c|c|}
\hline Dimension & Mean & SD & Min & Max & Median & Q1 & Q3 \\
\hline Intercommissural MA diameter (mm) & 28.0 & 4.9 & 17.5 & 43.0 & 28.0 & 24.7 & 31.0 \\
\hline Aorto-mural MA diameter (mm) & 20.0 & 4.6 & 8.0 & 34.9 & 19.0 & 16.9 & 23.5 \\
\hline MA area $\left(\mathrm{mm}^{2}\right)$ & 490.3 & 166.7 & 151.7 & 955.2 & 460.5 & 367.7 & 573.9 \\
\hline Circumference of the MA (mm) & 89.1 & 11.8 & 59.9 & 119.5 & 88.9 & 81.2 & 97.0 \\
\hline Base of the AML (mm) & 30.8 & 4.9 & 17.6 & 48.0 & 31.0 & 27.8 & 33.6 \\
\hline Height of the AML (mm) & 20.6 & 4.2 & 12.1 & 34.5 & 20.4 & 17.3 & 23.0 \\
\hline Base of the PML (mm) & 45.1 & 8.2 & 27.4 & 70 & 44.4 & 39.4 & 50.4 \\
\hline Height of the PML (mm) & 12.9 & 2.8 & 7.2 & 22.0 & 12.6 & 11.0 & 14.4 \\
\hline Base of the P1 (mm) & 12.5 & 3.9 & 4.7 & 30.4 & 12.1 & 10.2 & 14.4 \\
\hline Height of the P1 (mm) & 11.0 & 2.5 & 5.0 & 18.3 & 10.7 & 9.5 & 12.8 \\
\hline Base of the P2 (mm) & 19.9 & 5.8 & 5.8 & 41.0 & 19.8 & 16.0 & 23.4 \\
\hline Height of the P2 (mm) & 12.9 & 2.8 & 7.2 & 22.0 & 12.6 & 11.0 & 14.4 \\
\hline Base of the P3 (mm) & 12.7 & 4.0 & 4.2 & 26.0 & 12.1 & 10.2 & 14.4 \\
\hline Height of the P3 (mm) & 10.4 & 2.6 & 5.2 & 18.7 & 10.2 & 8.6 & 11.6 \\
\hline Base of the SL-C (mm) & 6.5 & 2.1 & 3.2 & 17.9 & 6.3 & 5.2 & 7.3 \\
\hline Height of the SL-C (mm) & 7.6 & 1.7 & 3.3 & 13.7 & 7.6 & 6.6 & 8.5 \\
\hline Base of the IS-C (mm) & 6.7 & 1.9 & 2.5 & 13.8 & 6.7 & 5.4 & 7.6 \\
\hline Height of the IS-C (mm) & 9.1 & 4.6 & 4.4 & 28.4 & 8.0 & 6.8 & 9.4 \\
\hline Common length of the mitral and aortic annulus (mm) & 22.3 & 3.7 & 11.8 & 34.0 & 22.1 & 20.0 & 23.5 \\
\hline
\end{tabular}

$S D$, Standard deviation; $Q 1, Q 3$, lower and upper quartiles; $M A$, mitral valve annulus; $A M L$, anterior mitral leaflet; $P M L$, posterior mitral leaflet; $P 1, P 2, P 3$, scallops of the posterior mitral leaflet; $S L-C$, superolateral commissure; $I S-C$, inferoseptal commissure.

no statistically significant differences in mitral annulus diameters or leaflets size, except for the PML base, which was smaller in valves with connected scallops when compared with classic valves $(39.7 \pm 8.9 \mathrm{~mm}$ vs $45.1 \pm 8.2 \mathrm{~mm} ; P=.006)$. However, we observed significantly increased density of tendinous cords attachments to the connected scallops. Mitral valves with only 2 similar in size scallops in the PML ( 3 cases) were observed. In 2 specimens, we found dichotomous $\mathrm{P} 2$, which have incompletely separated scallops to recognize PML with 4 scallops.

The AML is more consistent in anatomic structure than the PML. The AcS in AML was found only in $2.5 \%$ of all hearts (Figure 4,C). One heart had variations in both AML and PML connected P2 and P3 scallops, as well as AcS in AML at the superolateral commissure side. There was no statistically significant difference in AML and PML size or in any other mitral annulus dimensions when the AcS in AML is present, compared with classic valves.

The mean intertrigonal distance was $21.9 \pm 3.8 \mathrm{~mm}$ for all studied hearts, which constitute $24.6 \% \pm 4.4 \%$ of the mitral annulus circuit and was projected onto the AML. There were correlations among this parameter and age $(r=0.3 ; P<.001)$, heart weight $(r=0.2 ; P<.001)$, aorto-mural diameter $(r=0.33 ; P<.001)$, mitral annulus area $(r=0.26 ; P<.001)$ and circumference $(r=0.38$; $P<.001)$, AML height $(r=0.2 ; P=.005)$, and aortic annulus diameter $(r=0.2 ; P=.009)$, but not with the intercommissural diameter.

Within the mitral isthmus line, the great cardiac vein was present in $98 \%$ of cases and the left circumflex coronary artery was present in $57 \%$, whereas the branch of the right coronary artery was seen in $1.5 \%$. The great cardiac vein was located at a mean distance of $7.3 \pm 5.3 \mathrm{~mm}$ from the mitral annulus, whereas the left circumflex coronary artery was situated $7.9 \pm 5.1 \mathrm{~mm}$ from the mitral annulus. The mean distance between the left atrial appendage ostium and mitral annulus was $14.2 \pm 4.8 \mathrm{~mm}$. There were no other significant differences in any of the measured parameters between the sexes and no other significant correlations with donor's weight, BMI, or body surface area.

\section{DISCUSSION}

It is worth emphasizing that the mitral valve has just 2 main leaflets (no cusps): anterior (aortic) and posterior (mural). The leaflets are connected with 2 commissures: inferoseptal and superolateral (also, less frequently, called "commissural leaflets" or "commissural zones/areas"). To our knowledge, this is the case for all hearts. Furthermore, the leaflets can be divided into scallops. The PML is anatomically divided into 3 scallops: P1, P2, and P3. In contrast, the AML has no anatomic indentations for scallops, but A1, A2, A3 regions (that oppose the scallops of the PML) are distinguished by clinicians. ${ }^{2}$ The scallops 
TABLE 2. Frequency of occurrences of mitral valve anatomic variants

\begin{tabular}{|c|c|c|c|}
\hline Variant of the mitral valve & All $(\%)$ & Female $(\%)$ & Male $(\%)$ \\
\hline Total & $200(100)$ & $50(100)$ & $150(100)$ \\
\hline Classic mitral valve & $141(70.5)$ & $32(64)$ & 109 (72.7) \\
\hline Posterior leaflet variants & $55(27.5)^{*}$ & $18(36)$ & $37(24.7)^{*}$ \\
\hline AcS in PML between P3 and IS-C & $14(7)$ & $3(6)$ & $11(7.3)$ \\
\hline AcS in PML between P1 and SL-C & $8(4)$ & $4(8)$ & $4(2.7)$ \\
\hline AcS in PML between P1 and P2 & $3(1.5)$ & $1(2)$ & $2(1.3)$ \\
\hline AcS in PML between $\mathrm{P} 2$ and $\mathrm{P} 3$ & $3(1.5)$ & $1(2)$ & $2(1.3)$ \\
\hline $2 \mathrm{AcS}$ in $\mathrm{PML}$ & $4(2)$ & 0 & $4(2.7)$ \\
\hline Connections of scallops: $\mathrm{P} 1+\mathrm{P} 2$ & $6(3)$ & 0 & $6(4)$ \\
\hline Connections of scallops: P2 $+\mathrm{P} 3$ & $8(4)^{*}$ & $6(12)$ & $2(2.7)^{*}$ \\
\hline Connections of scallops: $\mathrm{P} 1+\mathrm{P} 2+\mathrm{P} 3$ & $4(2)$ & $2(4)$ & $2(2.7)$ \\
\hline 2 scallops in PML & $3(1.5)$ & 0 & $3(2)$ \\
\hline Dichotomous P2 & $2(1)$ & $1(2)$ & $1(0.7)$ \\
\hline Anterior leaflet variants & $5(2.5)^{*}$ & 0 & $5(3.3)^{*}$ \\
\hline AcS in AML at the IS-C side & $2(1)$ & 0 & $2(1.3)$ \\
\hline AcS in AML at the SL-C side & $3(1.5)^{*}$ & 0 & $3(2)^{*}$ \\
\hline
\end{tabular}

$A c S$, Accessory scallop; $P M L$, posterior mitral leaflet; $P 1, P 2, P 3$, scallops of the posterior mitral leaflet; $I S$ - $C$, inferoseptal commissure; $S L-C$, superolateral commissure; $A M L$, anterior mitral leaflet. *One heart with abnormalities in posterior and anterior leaflets.

are separated from each other by indentations. AcS could be described in both the AML and the PML. We highly recommended the use of this simple and practical terminology to unify the results of further studies and to facilitate understanding of the mitral valve structure by clinicians. ${ }^{12,13}$

Some authors have described that the mitral valve has from 4 to even 6 leaflets (or cusps); however, they do not correctly refer to leaflets, but rather to scallops. ${ }^{14,15} \mathrm{We}$ want to emphasize that the normal mitral valve has only 2 leaflets, and variations are observed only in scallops. There are 3 described cases of the trileaflet mitral valve with the presence of 3 equal-size leaflets, 3 commissures, and 3 papillary muscles linking the 3 commissures; thus, this anomaly is rare. ${ }^{16-18}$ In those cases, the trileaflet mitral valve was present in combination with bicuspid aortic valve, ${ }^{16}$ hypertrophic cardiomyopathy, ${ }^{17}$ and subaortic valvar stenosis. ${ }^{18}$ However, it is difficult to exclude that they were not also associated with coexisting spontaneous closure of preexisting atrioventricular septal defects. ${ }^{19}$

The scallops can be easily identified by the presence of indentations, defined by us as slits from the free edge of the leaflet, which separate the scallops and are supported by the tendinous cords. However, there is not a consensus on the proper name of the cleavages that could be seen in mitral valve leaflets. The terms "cleft" and "indentation" are currently used and have different meanings. ${ }^{20}$ Incorrect implementation of the term "indentation," change of the original meaning of the term "cleft," and even further the creation of new exotic terms such as "cleft-like indentations" have no morphologic justifications. ${ }^{21}$ Incorrect terminology results from a lack of the detailed knowledge of the normal mitral valve anatomy and only introduces confusions. Thorough discussion of all the inconsistencies in the use of different terms for this simple entity is far beyond the scope of this study. We strongly recommend using the term "indentation" to define any cleavage in mitral valve leaflets that (1) do not reach the mitral annulus and (2) may be located at any point of the anterior or posterior leaflet and thus divide the leaflets into scallops; and (3) is supported by proper tendinous cord (indentation cord); (4) regardless of whether it is associated with the mitral regurgitation or prolapse or not. For the congenital, pathologic leaflet splits that may be located in the anterior or posterior leaflet and (1) reach the mitral annulus or (2) are not connected with the tendinous cords to the papillary muscle, the term "cleft" should be used. The other terms could be abandoned, because they have no morphologic justifications.

In $98 \%$ of hearts, Victor and Nayak ${ }^{22}$ described 1 to 5 slits (defined by us as indentations) in the PML that subdivide the PML into scallops (2-6 scallops). Three scallops were most commonly seen variant $(56 \%)$, followed by 4 in $15 \%$ and 5 in $6 \%$. No indentations were observed in AML. They also pointed out that the term "cleft" should not be used for such slits (indentations), because this term connotes a congenital defect. ${ }^{22}$ The commissural leaflets described by Degandt and colleagues ${ }^{23}$ refer to superolateral commissure and inferoseptal commissure in our study, and cannot be confused with AcSs. The commissures can be clearly distinguished from indentations by the presence of fan-shaped commissural tendinous cords; commissures also are more similar in geometry to scallops. ${ }^{24} \mathrm{We}$ can also distinguish indentations from the wrinkles that can be seen on the atrial surface of both leaflets. These wrinkles 
TABLE 3. Results of the measurements of most common anatomic variations in the mitral valve

\begin{tabular}{|c|c|c|c|c|}
\hline \multirow[b]{2}{*}{ Dimension } & \multicolumn{2}{|c|}{ AcS in PML between P1 and SL-C $(N=14)$} & \multicolumn{2}{|c|}{ AcS in PL between P3 and IS-C $(N=8)$} \\
\hline & Mean \pm SD & Min; max & Mean \pm SD & Min; $\max$ \\
\hline Intercommissural MA diameter (mm) & $26.3 \pm 5.5$ & $16.4 ; 35.2$ & $29.2 \pm 5.7$ & $21.0 ; 39.1$ \\
\hline Aorto-mural MA diameter (mm) & $16.9 \pm 2.9$ & $14.0 ; 22.5$ & $20.8 \pm 6.8$ & $10.8 ; 35.0$ \\
\hline MA area $\left(\mathrm{mm}^{2}\right)$ & $396.9 \pm 111.1$ & $256.8 ; 823.5$ & $535.2 \pm 246.0$ & $187.5 ; 1008.9$ \\
\hline Circumference of the MA (mm) & $86.1 \pm 15.2$ & $62.7 ; 111.8$ & $99.8 \pm 14.8$ & $77.6 ; 128.9$ \\
\hline Base of the AML (mm) & $24.8 \pm 4.9$ & $16.1 ; 29.8$ & $34.0 \pm 3.3$ & $28.0 ; 40.0$ \\
\hline Height of the AML (mm) & $18.5 \pm 3.9$ & $14.3 ; 24.8$ & $23.9 \pm 5.9$ & $15.3 ; 41.0$ \\
\hline Base of the PML (mm) & $49.1 \pm 10.4$ & $34.7 ; 64.4$ & $52.9 \pm 9.7$ & $36.9 ; 70.9$ \\
\hline Height of the PML (mm) & $11.2 \pm 2.6$ & $8.0 ; 20.8$ & $13.5 \pm 3.2$ & $8.8 ; 19.7$ \\
\hline Base of the P1 (mm) & $11.6 \pm 3.0$ & $8.0 ; 15.8$ & $12.7 \pm 3.8$ & $7.1 ; 19.2$ \\
\hline Height of the P1 (mm) & $11.5 \pm 2.5$ & $8.0 ; 14.6$ & $12.1 \pm 3.0$ & $8.0 ; 19.1$ \\
\hline Base of the P2 (mm) & $17.0 \pm 6.1$ & $7.0 ; 28.5$ & $17.4 \pm 4.6$ & $11.7 ; 25.0$ \\
\hline Height of the P2 (mm) & $11.2 \pm 2.6$ & $8.0 ; 20.8$ & $13.5 \pm 3.2$ & $8.8 ; 19.7$ \\
\hline Base of the P3 (mm) & $11.1 \pm 2.1$ & $7.2 ; 17.5$ & $13.5 \pm 4.1$ & $9.2 ; 22.0$ \\
\hline Height of the P3 (mm) & $9.3 \pm 2.1$ & $6.0 ; 17.5$ & $12.5 \pm 3.2$ & $8.9 ; 18.0$ \\
\hline Base of the SL-C (mm) & $6.2 \pm 2.6$ & $3.0 ; 11.4$ & $5.9 \pm 2.1$ & $4.0 ; 12.1$ \\
\hline Height of the SL-C (mm) & $7.1 \pm 1.7$ & $4.5 ; 9.3$ & $8.2 \pm 2.5$ & $4.3 ; 14.8$ \\
\hline Base of the IS-C (mm) & $6.0 \pm 3.2$ & $3.0 ; 12.4$ & $7.0 \pm 3.4$ & $4.2 ; 17.5$ \\
\hline Height of the IS-C (mm) & $8.6 \pm 3.5$ & $6.3 ; 16.9$ & $9.5 \pm 6.6$ & $4.8 ; 31.5$ \\
\hline Base of the AcS (mm) & $9.5 \pm 4.3$ & $4.7 ; 17.8$ & $9.3 \pm 2.6$ & $5.6 ; 14.5$ \\
\hline Height of the AcS (mm) & $9.3 \pm 1.7$ & $6.8 ; 12.2$ & $10.0 \pm 2.9$ & $5.0 ; 15.9$ \\
\hline Base of the connected scallops (mm) & - & - & - & - \\
\hline Height of the connected scallops (mm) & - & - & - & - \\
\hline
\end{tabular}

$A c S$, Accessory scallop; $P M L$, posterior mitral leaflet; $P 1, P 2, P 3$, scallops of the posterior mitral leaflet; $S L-C$, superolateral commissure; $P L$, posterior leaflet; $I S$ - $C$, inferoseptal commissure; $A M L$, anterior mitral leaflet; $S D$, standard deviation; $M A$, mitral valve annulus.

or leaflet pleating result from the need of adjust of the leaflet in systole to the geometry of left atrioventricular orifice and may be confused with indentations. After straightening the wrinkle, there is no slit extending from the leaflet's free edge and no division into 2 separate scallops. Quill and colleagues $^{13}$ described deviant clefts (properly deviant

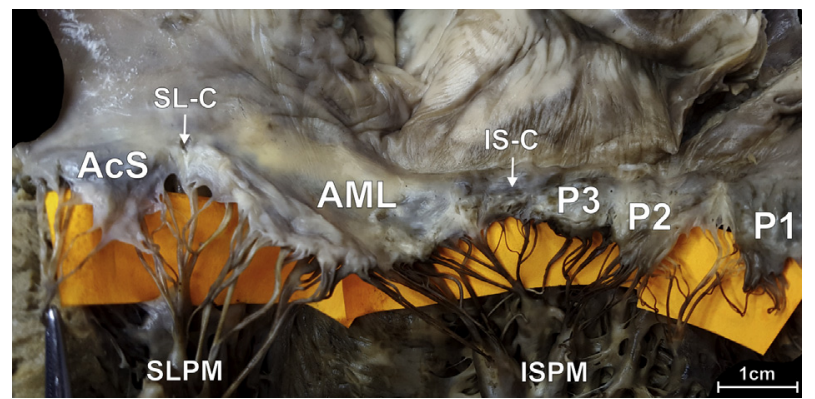

FIGURE 3. Cadaveric heart specimen. Mitral valve with AcS in PML between P1 and superolateral commissure. $S L$ - $C$, Superolateral commissure; $A c S$, accessory scallop; $A M L$, anterior mitral leaflet; $I S-C$, inferoseptal commissure; $P 1, P 2, P 3$, PML scallops; SLPM, superolateral papillary muscles; ISPM, inferoseptal papillary muscles. indentations), which, apart from "standard" clefts (standard indentations), were profusely localized in all regions of the PML and AML. In our opinion, these deviant indentations were mistakenly identified wrinkles, probably because of the endoscopic visualization of the mitral valve and the lack of the valve sectioning in that study.

Unsurprisingly, we found smaller values of intercommissural diameter, circumference, and area of the mitral annulus in female patients. Also, various positive correlations between annular dimensions and heart weight, as well as age, were discovered. In this study, most of the studied hearts $(70.5 \%)$ showed classic morphology. The mitral valve is composed of smaller PML and larger AML. However, the AML occupies only $35 \%$ of the mitral annulus circuit. The P2 scallop is the largest among PML scallops. Comparison of the current research results with other studies is difficult because there is a lack of similar studies, which focus on all mitral annulus and leaflets dimensions in heterogeneous autopsied material. There are several studies with relatively small sample sizes, mostly conducted in the past century, that selectively analyze leaflet and annular parameters. However, our morphometric results of the main 
TABLE 3. Continued

\begin{tabular}{|c|c|c|c|c|c|}
\hline \multicolumn{2}{|c|}{ Connections of scallops: $\mathbf{P 2}+\mathbf{P 3}(\mathbf{N}=\mathbf{8})$} & \multicolumn{2}{|c|}{ Connections of scallops: $\mathrm{P1}+\mathrm{P} 2(\mathrm{~N}=6)$} & \multicolumn{2}{|c|}{ AcS in AML $(N=5)$} \\
\hline Mean \pm SD & Min; $\max$ & Mean \pm SD & Min; $\max$ & Mean \pm SD & Min; $\max$ \\
\hline $26.5 \pm 3.6$ & $21.0 ; 33.1$ & $30.0 \pm 2.0$ & $27.0 ; 31.6$ & $30.5 \pm 3.7$ & $24.4 ; 33.6$ \\
\hline $20.1 \pm 4.5$ & $12.0 ; 26.9$ & $18.5 \pm 6.3$ & $13.0 ; 26.9$ & $19.0 \pm 4.7$ & $14.3 ; 26.9$ \\
\hline $471.0 \pm 174.5$ & $275.8 ; 823.5$ & $460.2 \pm 170.9$ & $314.3 ; 732.9$ & $528.8 \pm 184.8$ & $310.3 ; 823.5$ \\
\hline $87.0 \pm 13.9$ & $70.8 ; 107.2$ & $91.8 \pm 9.0$ & $82.5 ; 104.7$ & $95.4 \pm 4.3$ & $90.0 ; 100.9$ \\
\hline $29.5 \pm 2.8$ & $25.4 ; 33.7$ & $33.9 \pm 3.7$ & $27.0 ; 37.4$ & $28.4 \pm 4.6$ & $23.6 ; 33.6$ \\
\hline $19.4 \pm 3.1$ & $14.9 ; 24.7$ & $23.6 \pm 3.9$ & $19.2 ; 28.5$ & $20.5 \pm 3.8$ & $17.3 ; 27.0$ \\
\hline $42.5 \pm 10.8$ & $27.7 ; 59.4$ & $43.6 \pm 6.0$ & $38.9 ; 55.1$ & $51.7 \pm 8.2$ & $39.0 ; 59.4$ \\
\hline $13.1 \pm 3.6$ & $9.0 ; 18.2$ & $13.2 \pm 2.4$ & $10.9 ; 17.0$ & $16.3 \pm 5.1$ & $9.1 ; 20.8$ \\
\hline $13.3 \pm 3.0$ & $8.5 ; 16.8$ & - & - & $11.6 \pm 1.6$ & $10.0 ; 13.9$ \\
\hline $11.1 \pm 2.6$ & $7.3 ; 14.6$ & - & - & $11.3 \pm 2.7$ & $8.2 ; 14.6$ \\
\hline- & - & - & - & $25.1 \pm 5.3$ & $17.3 ; 28.5$ \\
\hline- & - & - & - & $16.3 \pm 5.1$ & $9.1 ; 20.8$ \\
\hline- & - & $12.4 \pm 2.7$ & $7.9 ; 16.0$ & $13.6 \pm 4.5$ & $9.1 ; 17.5$ \\
\hline- & - & $12.7 \pm 1.8$ & $10.8 ; 15.0$ & $12.0 \pm 4.1$ & $8.8 ; 17.5$ \\
\hline $7.5 \pm 2.4$ & $4.4 ; 11.3$ & $6.9 \pm 2.2$ & $4.8 ; 10.4$ & $7.1 \pm 2.5$ & $3.8 ; 9.6$ \\
\hline $7.1 \pm 1.9$ & $4.4 ; 11.4$ & $7.3 \pm 1.7$ & $4.2 ; 8.9$ & $7.4 \pm 1.0$ & $6.0 ; 8.5$ \\
\hline $7.6 \pm 2.6$ & $4.4 ; 11.4$ & $7.4 \pm 1.9$ & $5.8 ; 10.4$ & $8.2 \pm 3.0$ & $4.6 ; 11.9$ \\
\hline $8.7 \pm 1.6$ & $6.5 ; 10.8$ & $7.9 \pm 1.1$ & $6.0 ; 9.0$ & $9.0 \pm 2.7$ & $6.9 ; 13.1$ \\
\hline- & - & - & - & $8.3 \pm 1.8$ & $6.0 ; 10.6$ \\
\hline- & - & - & - & $13.1 \pm 2.8$ & $10.0 ; 16.6$ \\
\hline $29.3 \pm 9.8$ & $18.0 ; 45.5$ & $31.2 \pm 5.5$ & $27.0 ; 42.0$ & - & - \\
\hline $13.1 \pm 3.6$ & $9.0 ; 18.2$ & $13.2 \pm 2.4$ & $10.9 ; 17.0$ & - & - \\
\hline
\end{tabular}

mitral annulus dimensions and leaflet height and base are consistent with the results of other authors. ${ }^{15,24-26}$

In the $29.5 \%$ of valves, range of variation could be observed. The PML scallops can vary in number (2-5), and the accessory or connection of the scallops may occur in all PML regions. The AML is more constant than the PML, and although the AcS may occur only at the commissural ends, it is not found in the central zone. The variation in scallops number has an embryologic origin and is probably caused by disturbed delamination of the mitral valve apparatus from atrioventricular cushion tissue and further remodeling of the leaflets to provide a tight seal of the left atrioventricular orifice. ${ }^{27}$

Accessory and connected scallops can have a significant impact on mitral regurgitation development and its further surgical or transcatheter repair. First, the variations in scallop division may predispose to mitral insufficiency. We observed that small AcS in the PML usually have their own, independent scallop tendinous cords, whereas classic PML scallops usually are connected to each other by a complex network of tendinous cords. Insufficiency of even a single tendinous cord connected to AcS may be hemodynamically significant. Moreover, division of the PML into more than 3 standard scallops is a recognized factor for the mitral insufficiency. ${ }^{28}$ On the other hand, connected scallops, because of the lack of the indentations and scanty pleating of the leaflet, may not fit properly into the geometry of the atrioventricular orifice and thus predispose to regurgitation. Second, the variations may affect the mitral valve repair. Both in edge-to-edge stitch placement and MitraClip approach to mitral valve repair, the AML and PML are gripped to join at the location of regurgitation. These techniques most commonly are used in patients with A2/P2 prolapse. ${ }^{29,30}$ The middle zone (A2) of the AML is the most constant area of the mitral valve and should not generate those problems that may be encountered in the relatively highly variable $\mathrm{P} 2$ scallop. A small size of the AcS or a dense network of tendinous cord under the connected scallop may hinder these procedures. Because of the complexity of the mitral valve apparatus and the possibility of variations, it is likely that a combination of the methods may be required to provide successful mitral valve repair. Unfortunately, our results show that the presence of variation cannot be easily predicted by the 

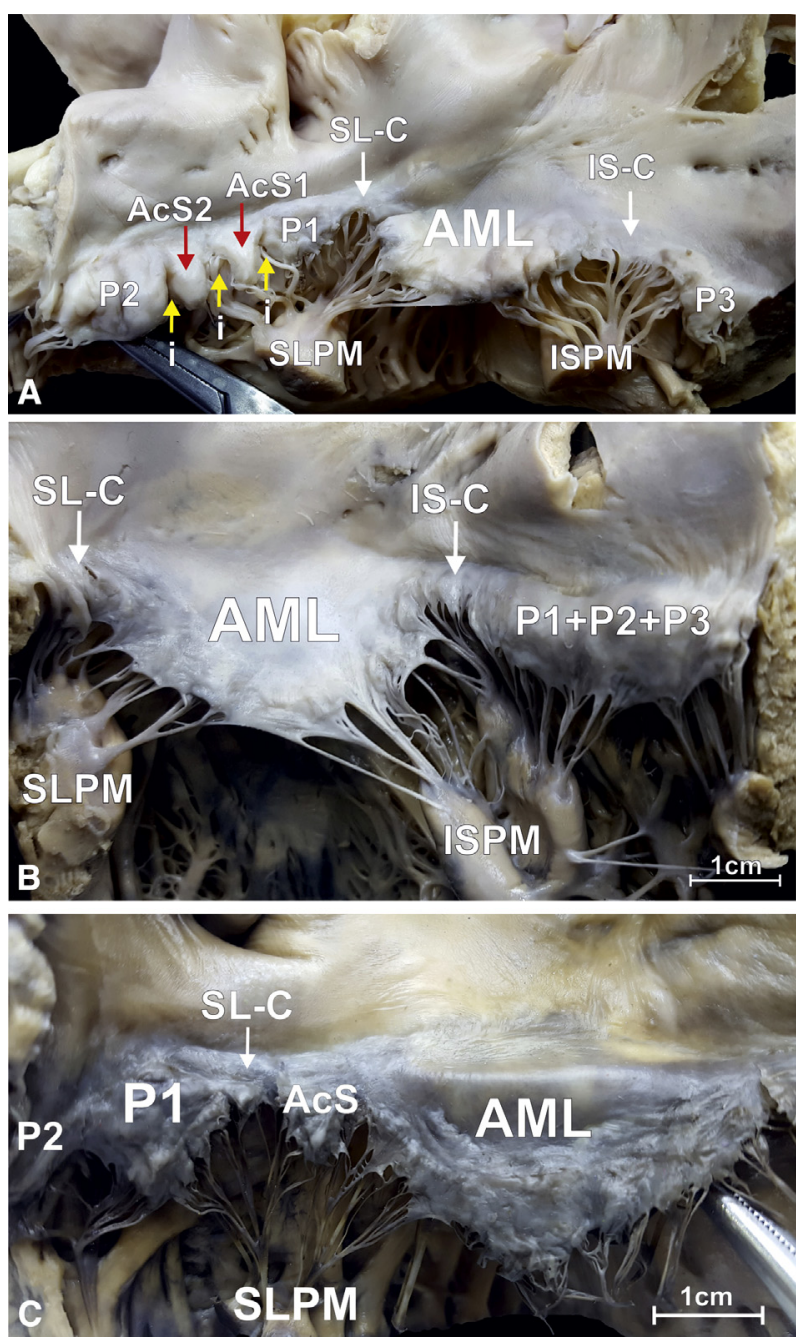

FIGURE 4. Cadaveric heart specimens. A, Mitral valve with 2 AcSs ( $A c S 1$ and $A c S 2$ ) in the PML, located between P1 and P2. B, Mitral valve with all connected scallops in the PML. C, Mitral valve with AcS in the AML at the superolateral commissure side. $S L-C$, superolateral commissure; $I S-C$, inferoseptal commissure; $P 1, P 2, P 3$, PML scallops; $A M L$, anterior mitral leaflet; $i$, indentations; $S L P M$, superolateral papillary muscles; $I S P M$, inferoseptal papillary muscles.

annulus diameters or leaflets size, which was suggested by Deopujari and colleagues. ${ }^{26}$ Only preprocedural and intraprocedural imaging may reveal the scallops' anatomic variations. ${ }^{5,6,31}$ Three-dimensional echocardiography allows for evaluation of mitral valve morphology, including annulus, subvalvar apparatus, and leaflets with distinguished scallops. Diameter, circumference and area of the mitral annulus, height and thickness of scallops, and all variations in valvar leaflets could be precisely assessed in real time. $^{32}$

The intertrigonal distance, which represents aorticmitral valvar continuity, is crucial when planning the treatment of aortic or mitral valve stenosis, caused by massive, overlapping calcification. Knowledge of this parameter may help to determine the proper mitral valve annuloplasty ring size during minimally invasive cardiac surgery. ${ }^{33} \mathrm{We}$ found that intertrigonal distance dilates with age and heart weight, but not with BMI. It seems that the aortic annulus diameter is mostly responsible for the intertrigonal distance length.

One has to appreciate the anatomic features that are near the mitral valve. ${ }^{5}$ Relationships between the mitral annulus and the great cardiac vein, coronary sinus, or left circumflex coronary artery are substantial to minimize the occurrence of serious ischemic complications during percutaneous mitral valve interventions. ${ }^{34}$ Knowledge of this is mandatory for percutaneous mitral annuloplasty through the coronary sinus. ${ }^{35}$ There are described cases of left circumflex coronary artery occlusion during mitral valve surgery. ${ }^{36}$ Moreover, the distance from the mitral annulus to the left atrial appendage orifice could help to select suitable patients for percutaneous left atrial appendage transcatheter occlusion. Appropriate implantation of the device prevents potential interaction of the disc and the mitral valve. ${ }^{37}$

\section{Study Limitations}

The main limitation of this study is the potential bias in the measurements because all of them were performed after formaldehyde fixation, which may change the size and shape of the heart. However, prior studies have shown that the use of $10 \%$ paraformaldehyde does not cause significant changes in atrial tissue and tendinous cords dimensions; the dimensions of fixed hearts are similar to those before fixation. ${ }^{8}$ Moreover, the dimensions of the cadaveric tissue may differ slightly from in vivo dimensions of the mitral valve components. In regard to the dynamic geometry of the mitral valve complex, we cannot speculate about changes in leaflet dimensions within the cardiac cycle. Also, the dominance of the coronary arteries was not described in our study population. However, we believe that these limitations do not impede our morphologic analysis of relationships between individual heart structures and their relative dimensions.

\section{CONCLUSIONS}

This study characterized the morphologic variability and reports the morphometry of the mitral valve leaflets and scallops. In all cases, the mitral valve is built by 2 main leaflets with possible variants in scallops $(29.5 \%)$. The variations are largely associated with PML and are mostly related to the presence of AcS. Anatomically, the AML is not divided into scallops, but could have AcS (2.5\%). The intertrigonal distance dilates with age and heart weight, but not with the BMI. Understanding the anatomy of the mitral valve leaflets helps with the planning and performing of mitral valve repair procedures. Variations in scallops may affect repair procedures, but unfortunately cannot be predicted by any of the annular sizes. 


\section{Conflict of Interest Statement}

Authors have nothing to disclose with regard to commercial support.

\section{References}

1. Polner P. In: Traité d'anatomie Humaine, Vol. II. Paris, France: Masson; 1902.

2. Ho SY. Anatomy of the mitral valve. Heart. 2002;88:iv5-10.

3. Feldman T, Guerrero M. Transcatheter direct mitral valve annuloplasty: a brief review. EuroIntervention. 2015;11:W53-7.

4. Debonnaire P, Palmen M, Marsan NA, Delgado V. Contemporary imaging of normal mitral valve anatomy and function. Curr Opin Cardiol. 2012;27:455-64.

5. Thériault-Lauzier P, Mylotte D, Dorfmeister M, Spaziano M, Andalib A, Mamane S, et al. Quantitative multi-slice computed tomography assessment of the mitral valvular complex for transcatheter mitral valve interventions part 1: systematic measurement methodology and inter-observer variability. EuroIntervention. 2016;12:e1011-20.

6. Thériault-Lauzier P, Dorfmeister M, Mylotte D, Andalib A, Spaziano M, Blanke P, et al. Quantitative multi-slice computed tomography assessment of the mitral valvular complex for transcatheter mitral valve interventions part 2: geometrical measurements in patients with functional mitral regurgitation. EuroIntervention. 2016;12:e1021-30.

7. Natarajan N, Patel P, Bartel T, Kapadia S, Navia J, Stewart W, et al. Peri-procedural imaging for transcatheter mitral valve replacement. Cardiovasc Diagn Ther. 2016;6:144-59.

8. Hołda MK, Klimek-Piotrowska W, Koziej M, Piatek K, Hołda J. Influence of different fixation protocols on the preservation and dimensions of cardiac tissue. J Anat. 2016;229:334-40.

9. Hołda MK, Koziej M, Hołda J, Tyrak K, Piątek K, Bolechała F, et al. Anatomic characteristics of the mitral isthmus region: the left atrial appendage isthmus as a possible ablation target. Ann Anat. 2017;210:103-11.

10. Klimek-Piotrowska W, Hołda MK, Piątek K, Koziej M, Hołda J. Normal distal pulmonary vein anatomy. PeerJ. 2016;4:e1579.

11. Hołda MK, Koziej M, Hołda J, Tyrak K, Piątek K, Krawczyk-Ożóg A, et al. Spatial relationship of blood vessels within the mitral isthmus line. Europace. February 14, 2017 [Epub ahead of print].

12. Carpentier A, Branchini B, Cour JC, Asfaou E, Villani M, Deloche A, et al. Congenital malformations of the mitral valve in children. Pathology and surgical treatment. J Thorac Cardiovasc Surg. 1976;72:854-66.

13. Quill JL, Hill AJ, Laske TG, Alfieri O, Iaizzo PA. Mitral leaflet anatomy revisited. J Thorac Cardiovasc Surg. 2009;137:1077-81.

14. Yacoub M. Anatomy of the mitral valve chordae and cusps. In: Kalmanson D, ed. The Mitral Valve. A Pluridisciplinary Approach. London: Edward Arnold; 1976: $15-20$.

15. Gunnal SA, Farooqui MS, Wabale RN. Study of mitral valve in human cadaveric hearts. Heart Views. 2012;13:132-5.

16. Chachoua A, Abboub B, Ghemri S, Hammoundi N. Trileaflet mitral valve associated with a bicuspid aortic valve. J Cardiol Cases. 2016;13:37-9.

17. Irwin RB, Macnab A, Schmitt M. Tri-leaflet mitral valve in combination with hypertrophic cardiomyopathy. Eur Heart J. 2011;32:534.

18. Kozak MF, Sivanandam S, De Marchi CH, Kozak AC, Croti UA, Moscardini AC, et al. A trileaflet mitral valve with three papillary muscles: brand new echocardiographic findings. Congenital Heart Dis. 2011;6:70-3.

19. Baumgartner H, Bonhoeffer P, De Groot NM, de Haan F, Deanfield JE, Galie N, et al. ESC Guidelines for the management of grown-up congenital heart disease (new version 2010). Eur Heart J. 2010;31:2915-57.
20. Nii M. What is this cleavage of mitral valve - Commissure, indentation, cleft, or cleft-like indentation? J Cardiol Cases. 2016;13:40-1.

21. Mantovani F, Clavel MA, Vatury O, Suri RM, Mankad SV, Malouf J, et al. Cleftlike indentations in myxomatous mitral valves by three-dimensional echocardiographic imaging. Heart. 2015;101:1111-7.

22. Victor S, Nayak VM. Definition and function of commissures, slits and scallops of the mitral valve: analysis in 100 hearts. Asia Pac J Thorac Cardiovasc Surg. 1994;3:10-6.

23. Degandt AA, Weber PA, Saber HA, Duran CM. Mitral valve basal chordae: comparative anatomy and terminology. Ann Thorac Surg. 2007;84:1250-5.

24. Ranganathan N, Lam JH, Wigle ED, Silver MD. Morphology of the human mitral valve. II. The value leaflets. Circulation. 1970;41:459-67.

25. Patil D, Mehta C, Prajapati P. Morphology of mitral valve in human cadavers. Int J Cardiol. 2008;7:8.

26. Deopujari R, Sinha U, Athavale SA. Anatomy of left atrioventricular valve (mitral valve) leaflets in adult Indian cadavers. Int J Morphol. 2013;31: 1276-81.

27. Oosthoek PW, Wenink AC, Vrolijk BC, Wisse LJ, DeRuiter MC, Poelmann RE et al. Development of the atrioventricular valve tension apparatus in the human heart. Anat Embryol (Berl). 1998;198:317-29.

28. Kalangos A, Oberhansli I, Khatchatourian G, Friedli B, Faidutti B. Multipleleaflet mitral valve as a rare cause of congenital mitral insufficiency. Ann Thorac Surg. 1997;63:1452-5.

29. Alfieri O, Maisano F, Colombo A, Pappone C, La Canna G, Zangrillo A. Percutaneous mitral valve repair: an attractive perspective and an opportunity for teamwork. Ital Heart J. 2004;5:723-6.

30. Alfieri O, De Bonis M, Lapenna E, Regesta T, Maisano F, Torracca L, et al "Edge-to-edge" repair for anterior mitral leaflet prolapse. Semin Thorac Cardiovasc Surg. 2004; 16:182-7.

31. Garbi M, Monaghan MJ. Quantitative mitral valve anatomy and pathology. Echo Res Pract. 2015;2:R63-72.

32. Ghulam AS, Fusini L, Tamborini G, Muratori M, Gripari P, Mapelli M, et al Detailed transthoracic and transesophageal echocardiographic analysis of mitral leaflets in patients undergoing mitral valve repair. Am J Cardiol. 2016;118: 113-20.

33. Morishima K, Inatomi Y, Ohnishi Y. Inter-trigonal distance measured by real-time three-dimensional transesophageal echocardiography for predicting the size of mitral annuloplasty ring. J Cardiothorac Vasc Anesth. 2015;29:S31.

34. Spencer JH, Prahl G, Iaizzo PA. The prevalence of coronary sinus and left circumflex artery overlap in relation to the mitral valve. J Interv Cardiol. 2014;27:308-16.

35. Lansac E, Di Centa I, Al Attar N, Messika-Zeitoun D, Raffoul R, Vahanian A, et al. Percutaneous mitral annuloplasty through the coronary sinus: an anatomic point of view. J Thorac Cardiovasc Surg. 2008;135:376-81.

36. Grande AM, Fiore A, Massetti M, Viganò M. Iatrogenic circumflex coronary lesion in mitral valve surgery: case report and review of the literature. Tex Heart Inst J. 2008;35:179-83.

37. Wolfrum M, Attinger-Toller A, Shakir S, Gloekler S, Seifert B, Moschovitis A, et al. Percutaneous left atrial appendage occlusion: effect of device positioning on outcome. Catheter Cardiovasc Interv. 2016;88:656-64.

Key Words: mitral valve, bicuspid valve, mitral leaflets, accessory scallop, human heart, connected scallops, clefts, indentations 